\title{
An improved Bergeron differential protection for half-wavelength AC transmission line
}

\author{
Pengfei Shao ${ }^{1, *}, \mathrm{Yu} \mathrm{Li}^{1}$, Ruiming Fang ${ }^{1}$ and Xinghua Guo ${ }^{1}$ \\ ${ }^{1}$ Huaqiao University,361021 Xiamen, China
}

\begin{abstract}
Half-wavelength AC transmission line has the characteristics of long transmission distance and high voltage level, and its fault characteristics are significantly different from conventional transmission line. In order to reduce the interference of distributed capacitive current on half-wavelength AC transmission line on the calculation of current differential protection, this paper proposes a new current differential protection scheme based on Bergeron model. In order to solve the problem of small differential current located at the midpoint when a short circuit fault occurs, a solution using different methods to calculate setting value in different areas is proposed. The protection can move quickly near the terminal and delay to act in the middle area. After simulation and verification on the PSCAD experimental platform, it is found that when there is a fault at both terminals of the line, the protection can quickly operate in about $10 \mathrm{~ms}$; when fault occurs in the middle area, the protection can delay its operation. The experimental results show that the various actions and performance of the protection device can meet the requirements of safe operation of halfwavelength transmission line.
\end{abstract}

\section{Introduction}

Half-wavelength AC transmission refers to the transmission technology near a half wave (the line length is $3000 \mathrm{~km}$ when the transmission frequency is $50 \mathrm{~Hz}$, and $2500 \mathrm{~km}$ when the frequency is $60 \mathrm{~Hz}$ ). Halfwavelength AC transmission technology has better economic efficiency in ultra-long-distance power transmission and has great development potentiality. Compared with traditional AC transmission technology, half-wavelength $\mathrm{AC}$ transmission technology has significant economic and technical advantages, reflected in the following points: less voltage loss, good stability, no need to install reactive power compensation devices, no need to set up intermediate stations, economy, etc. With the advancement of the global energy Internet, half-wavelength transmission as a solution suitable for large-scale intercontinental power transmission has received widespread attention.

The transmission distance of a half-wavelength AC transmission line is a half-wave. The voltage and current are not only a function of time, but a function of distance. It cannot be regarded as a lumped parameter line. Thus, the electrical characteristics and fault characteristics of the half-wavelength transmission line also have a significant difference from conventional line. There are a great number of problems in actual operation, for example, it is only applicable for the line whose length is closed to half-wavelength; it has huge potential current and overvoltage when short circuit fault occurs and the traditional relay protection has no applicability on half- wavelength transmission line. Due to the superior economic efficiency of half-wavelength transmission line, scholars at home and abroad have conducted a lot of research on its characteristics for decades, such as line tuning [1]-[2], submersible current [3]-[4], overvoltage [5]-[7], insulation coordination [8], the evaluation of economic and reliability [9], protection [10]-[13], etc. However, the research on the relay protection for halfwavelength transmission line has just started.

This article focuses on the research of relay protection for half-wavelength transmission line. Since the electrical characteristics and fault characteristics of half-wavelength transmission line are significantly different from those of conventional lines, many problems will appear when traditional relay protection schemes are applied into half-wavelength transmission line.

For example, a lot of problems appear when conventional current differential protection is applied into the half-wavelength transmission line:

1) The voltage characteristic curve and current characteristic curve are non-linear, non-monotonic, the capacitive current along the line cannot be accurately calculated;

2) When the fault occurs at the midpoint of the line, the differential current is close to 0 , how to choose the action value;

3) Transmission line has a long channel delay and the transmission time of electromagnetic wave gets longer.

In order to solve the above problems, this paper proposes a new differential protection scheme:

\footnotetext{
* Corresponding Pengfei Shao: Shaopengfei@hqu.edu.cn
} 
1) The line adopts the Bergeron model. Bergeron model equals the distributed parameter element to the lumped parameter element, which eliminates the influence of the distributed capacitance current for protect;

2) In order to solve the problem of small fault current which is located at the midpoint of the line, a low setting value is used to improve the protection sensitivity;

3) In order to reduce the protection action time, the protection adopts a two-stage quick action and a delay action in the middle area, and the two terminals act quickly. On the premise that the protection can operate correctly, the quick action is guaranteed to the greatest extent.

Experimental results show that the various actions and performances of the protection device can meet the requirements for safe operation of half-wavelength transmission line.

\section{IMPROVED BERGERON DIFFERENTIAL PROTECTION METHOD FOR HALF-WAVELENGTH AC TRANSMISSION LINE}

Compared with traditional relay protection methods, Bergeron differential protection has the advantage of reducing the impact of distributed capacitive current to conventional current differential protection. Its principle is still based on Kirchhoff 's law. Although the transmission line is $3000 \mathrm{~km}$, the use of Bergeron differential protection still has good effects.

As the half-wavelength transmission system shown in Figure 1, Bergeron differential protection can be implemented at the $\mathrm{M}$ terminal. The detailed steps are as follows:

1) The transient instantaneous values of the threephase voltage and current at the $\mathrm{M}$ terminal which can be obtained by the relay protection measuring device, are respectively recorded as $u_{m}(t)$ and $i_{m}(t)$. The transient instantaneous value of the three-phase voltage and current at the $\mathrm{M}$ terminal which are obtained by synchronous measurement device and a low-delay optical fiber communication device, are respectively recorded as $u_{n}(t)$ and $i_{n}(t)$.

2) Use the Karrenbauer transform to eliminate the electromagnetic coupling between the three-phase line, then convert the mode values of the voltage and current in the time domain to those in the frequency domain by using Fourier transform. It is easy to get the fundamental wave component of voltage and current at time $t$, which are respectively recorded as $U_{m}(t), I_{m}(t), U_{n}(t)$ and $I_{n}(t)$.

3) The fundamental components of voltage and current at the $\mathrm{M}$ and $\mathrm{N}$ terminals at time $t-\tau$ are $U_{m}(t-\tau)$, $I_{m}(t-\tau), U_{n}(t-\tau)$ and $I_{n}(t-\tau)$. For the $\mathrm{M}$ terminal, the current at time $t$ can be described as:

$$
I_{s m}(t)=\frac{U_{m}(t)}{Z_{c}}+I_{m n}(t-\tau)
$$

4) The specific judgment basis for the Bergeron differential protection at the $\mathrm{M}$ terminal is as follows:

$$
I_{m d}=\left|I_{m}-I_{s m}\right|>I_{m d s e t}
$$

The Bergeron differential current is directly related to the current at the fault point. The current at the fault point can be described by the fault distance function, and its specific expression is as follows:

$$
\dot{I}_{f m}=\frac{\dot{E}_{m}}{Z_{m} \cos \left(\frac{2 \pi}{\lambda} x_{1}\right)+j Z_{c} \sin \left(\frac{2 \pi}{\lambda} x_{1}\right)}
$$

According to formula (3), the current at the short circuit point can be calculated by following expression:

$$
\begin{gathered}
\dot{I}_{f}=\frac{\dot{E}_{m}}{Z_{m} \cos \left(\frac{2 \pi}{\lambda} x_{1}\right)+j Z_{c} \sin \left(\frac{2 \pi}{\lambda} x_{1}\right)} \\
+\frac{\dot{E}_{n}}{Z_{n} \cos \left(\frac{2 \pi}{\lambda} x_{2}\right)+j Z_{c} \sin \left(\frac{2 \pi}{\lambda} x_{2}\right)}
\end{gathered}
$$

Considering the special case when a three-phase short circuit fault occurs at the midpoint of a halfwavelength line, there are:

$$
\dot{I}_{f}=\frac{\dot{E}_{m}+\dot{E}_{n}}{j Z_{c}}
$$

Considering the special case when a three-phase short circuit fault occurs at the $\mathrm{M}$ terminal of a halfwavelength line, there are:

$$
\dot{I}_{f}=\frac{\dot{E}_{m}}{Z_{m}}-\frac{\dot{E}_{n}}{Z_{n}}
$$

For the actual half-wavelength transmission system, the system voltages at the $\mathrm{M}$ terminal and the $\mathrm{N}$ terminal are generally equal in magnitude and opposite in phase. When a short circuit fault occurs at the midpoint of the line of the system, the Bergeron differential current is approximately equal to the short circuit fault current, which is 0 ; when a short circuit fault occurs at the $M$ and $\mathrm{N}$ terminals, the short circuit current or the Bergeron differential current is very large. The conditional Bergeron differential protection is obviously effective when a fault occurs at the $\mathrm{M}$ and $\mathrm{N}$ terminals of the line. But when the fault occurs near the midpoint of the line, the effect of the Bergeron differential protection is no longer obvious and there may even be a dead zone in the relay protection, which may cause the protection device refuses to act when short circuit fault occurs. In order to improve the reliability of the Bergeron differential protection on half-wavelength transmission system, it needs to improve the sensitivity of the protection device.

The Bergeron differential protection scheme proposed in this paper divides the half-wavelength transmission line into an intermediate short circuit section (1000-2000 km of the line) and an external short circuit section of the line. It is known that there are such relationship between the electrical quantity at $\mathrm{M}$ terminal of the line and the distance of the fault: 


$$
\left\{\begin{array}{l}
\dot{U}_{m}=Z_{c} \frac{j \dot{E}_{m} \sin \left(\frac{2 \pi}{\lambda} x_{1}\right)}{Z_{m} \cos \left(\frac{2 \pi}{\lambda} x_{1}\right)+j Z_{c} \sin \left(\frac{2 \pi}{\lambda} x_{1}\right)} \\
\dot{I}_{m}=\frac{\dot{E}_{m} \cos \left(\frac{2 \pi}{\lambda} x_{1}\right)}{Z_{m} \cos \left(\frac{2 \pi}{\lambda} x_{1}\right)+j Z_{c} \sin \left(\frac{2 \pi}{\lambda} x_{1}\right)}
\end{array}\right.
$$

Supplement the criterion on the basis of the previous analysis can further improve the sensitivity. On the condition that the short circuit faults outside the area do not cause malfunctions, the short circuit faults in the area can be removed through appropriate delay operations. Equation (7) can be used as the theoretical basis for supplementing criterion. The internal resistance of the $\mathrm{M}$ terminal power source can be ignored, but the reactance value should be retained. After this simplified analysis, the power source impedance can only retain its imaginary part. Substitute impedance into the formula (7), the current at the $M$ terminal can be written as:

$$
\dot{I}_{m}=\frac{-j \dot{E}_{m}}{Z_{m}+Z_{c} \tan \left(\frac{2 \pi}{\lambda} x_{1}\right)}
$$

By the formula (8), it can be seen that when the short circuit fault occurs in the middle section (the area which is close to the midpoint of the line) the denominator terminals to be infinite. It makes the current value measured by the installation protection device very small, even may be less than the load current value. But when the short circuit fault occurs on the line outside the middle section, the current value measured by the installation protection device is very large, may be close to the value of terminal short circuit. By observing the value of the protection current, it is possible to judge whether the short circuit fault occurs in the middle section or outside it.

This paper adopts the Bergeron differential protection scheme with high sensitivity and low sensitivity which specific criterion satisfies the following formula:

$$
\begin{gathered}
I_{m d}>I_{m d s e t 1} \\
I_{m d}>I_{m d s e t 2} \\
I_{m}<I_{m s e t}
\end{gathered}
$$

Where $I_{m d s e t}$ is the setting value of low-sensitivity differential protection. It is slightly larger than the maximum differential current when a short circuit occurs outside the zone. Imdset 2 is the setting value of highsensitivity differential protection, which is based on the minimum short circuit current. It should be satisfied that Imdset 1 is greater than $I_{m d s e t 2 .}$ Imset is the setting value used to judge the fault section. The measured current value of the M terminal, $I_{m}$, is larger than the internal short circuit fault current in the middle section, but less than the external short circuit fault current.

If formula (9) is established, it can be judged that a serious short circuit fault occurs in the middle section of the line and the protection device needs to act immediately; if formula (10) and formula (11) are both established, it can be judged that the short circuit fault occurs in the middle section of the half-wavelength line and the protection device can act after the setting delay; if the formula (10) is established but formula (11) is not established, it can be judged that the short circuit fault occurs outside the area and the protection device does not act.

\section{SIMULATION VERIFICATION}

Build a half-wavelength $\mathrm{AC}$ transmission system as shown in Figure 1 in the power system simulation software PSCAD/EMTDC. The system uses a $1000 \mathrm{kV}$ UHV three-phase AC line, which both terminals are named $\mathrm{M}$ and $\mathrm{N}$ respectively. The electromotive force phasors of $\mathrm{M}$ terminal and $\mathrm{N}$ terminal are respectively $E_{\mathrm{m}}=1050 \angle 16.1^{\circ}$ and $E_{\mathrm{n}}=1000 \angle 180^{\circ}$. Zero sequence component and positive sequence component of internal resistance at $\mathrm{M}$ terminal and $\mathrm{N}$ terminal are represented by $Z_{\mathrm{m} 0}, Z_{\mathrm{n} 0}, Z_{\mathrm{m} 1}$ and $Z_{\mathrm{n} 1}$, where $Z_{\mathrm{m} 0}=Z_{\mathrm{n} 0}=Z_{\mathrm{m} 1}=Z_{\mathrm{n} 1}=30$ $\angle 89^{\circ} \Omega$.

The specific parameters of the unit length line include: zero sequence resistance $R_{0}$, positive sequence resistance $R_{1}$, zero sequence resistance $X_{L 0}$, positive sequence resistance $X_{L 1}$, zero sequence capacitive reactance $X_{C 0}$ and positive sequence capacitive reactance $X_{C l}, \quad$ Where $R_{0}=0.139706 \Omega / \mathrm{km}, \quad R_{1}=0.00647 \Omega / \mathrm{km}$, $X_{L 0}=0.876470 \Omega / \mathrm{km}, \quad X_{L 1}=0.25294 \Omega / \mathrm{km}$, $X_{C 0}=0.393547 \mathrm{M} \Omega \cdot \mathrm{km}, X_{C 1}=0.226413 \mathrm{M} \Omega \cdot \mathrm{km}$. In order to reduce the influence of overvoltage and overcurrent in the actual measurement, voltage transformer (PT) and current transformer $(\mathrm{CT})$ are put into operation at $\mathrm{M}$ terminal and $\mathrm{N}$ terminal, with their conversion ratios of $1000 \mathrm{kV} / 100 \mathrm{~V}$ and $5000 \mathrm{~A} / 1 \mathrm{~A}$ respectively.

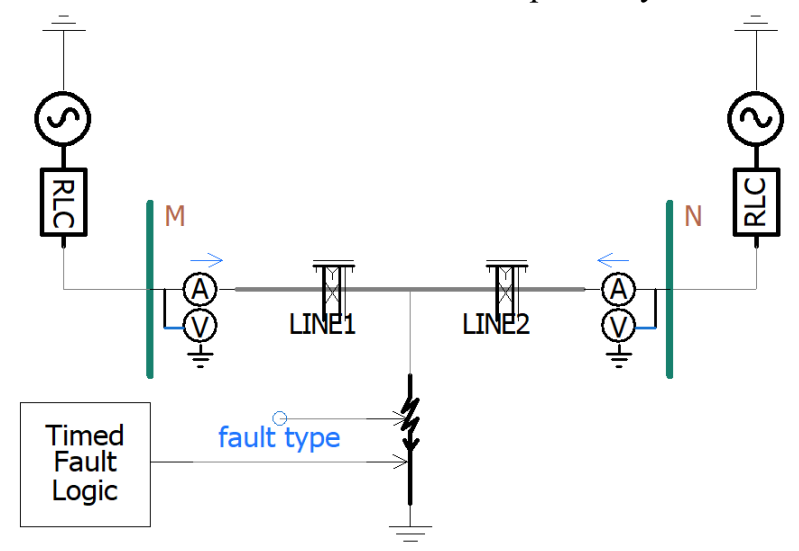

Figure 1. Simulation model of half-wavelength $\mathrm{AC}$ transmission system

For the $\mathrm{M}$ terminal, the electrical quantity changes with the short circuit fault location. It shows the change of voltage, current and impedance while the fault location is changed in Figure 2, where all values are measurement results of the secondary equipment. The result in the figure takes the $M$ terminal as the distance reference point, a short circuit scenario is set every 50 $\mathrm{km}$, and then the relevant electrical quantities are measured. 
When the half-wavelength $\mathrm{AC}$ transmission system is operating normally, the voltage, current, differential current and impedance of the M terminal keep constant. However, when a short circuit fault occurs in a halfwavelength $\mathrm{AC}$ transmission system, the voltage amplitude first increases and then decreases with the change of the short circuit distance. The voltage amplitude arrivals the maximum at $2850 \mathrm{~km}$, and the change rate of voltage amplitude is greater when the short circuit point is close to $3000 \mathrm{~km}$. When the short circuit point reaches the midpoint of the transmission line, the current amplitude of the M terminal gradually decreases and the rate of change becomes smaller and smaller. When the short circuit point exceeds the midpoint of the line, the current amplitude firstly increases and then decreases and the amplitude of the current also achieves the maximum value at $2850 \mathrm{~km}$. In the conventional protection scheme, two maximum values of the differential current appear at $150 \mathrm{~km}$ and $2850 \mathrm{~km}$ respectively with the change of the short circuit point. While the short circuit point is close to the midpoint of the line, the amplitude of the current is smaller, even close to zero at the midpoint which easily causes the relay protection device refuses to trip.

The amplitude of the impedance obtains the only maximum value at the midpoint of the line, and it is almost symmetric about the middle point of line. The phase angle of impedance is also almost symmetric about the midpoint of the line. When the short circuit occurs at the midpoint of the line, the phase angle of the impedance changes abruptly to 180 degrees.

After the above analysis, it can be known that when a short circuit fault occurs at the middle section of the line, that is, between $1000 \mathrm{~km}$ and $2000 \mathrm{~km}$, the conventional differential current will be close to zero; and when a short circuit fault occurs at the $\mathrm{M}$ and $\mathrm{N}$ terminals of the line, the conventional differential current is very large. The conventional differential protection can achieve better results when a fault occurs at the $\mathrm{M}$ and $\mathrm{N}$ terminals of the line, but when the fault occurs in middle section, that is the area between $1000 \mathrm{~km}$ and $2000 \mathrm{~km}$, the effect of the conventional differential protection is no longer obvious, there even may be a dead zone in the relay protection, which causes the normal cut-off operation cannot be performed after the short circuit fault occurs. Therefore, the traditional differential protection needs to be improved urgently.

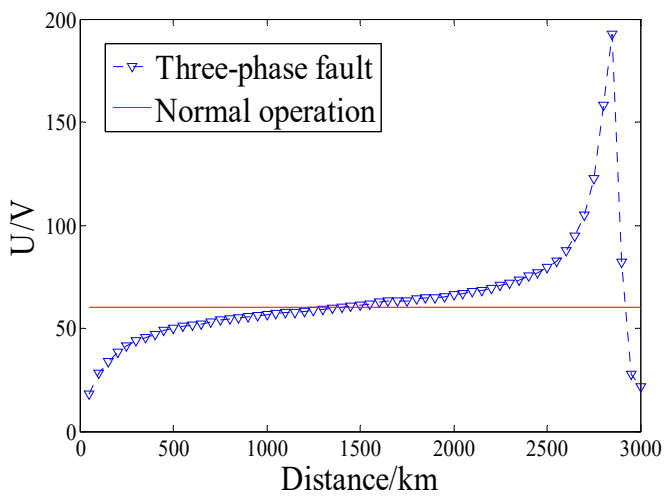

(a) The voltage of M terminal

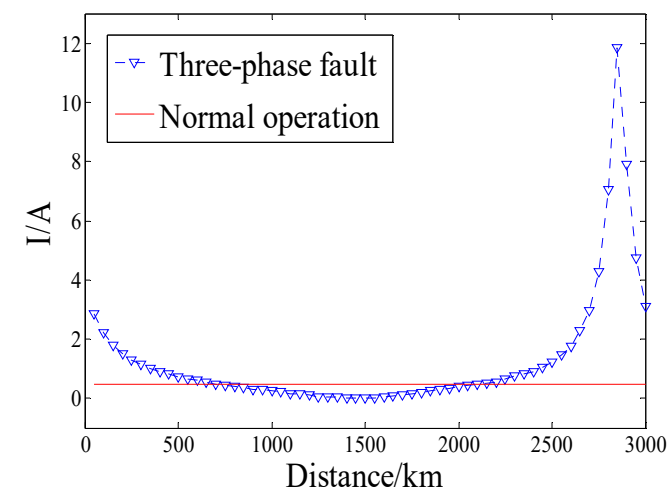

(b) The current of $\mathrm{M}$ terminal

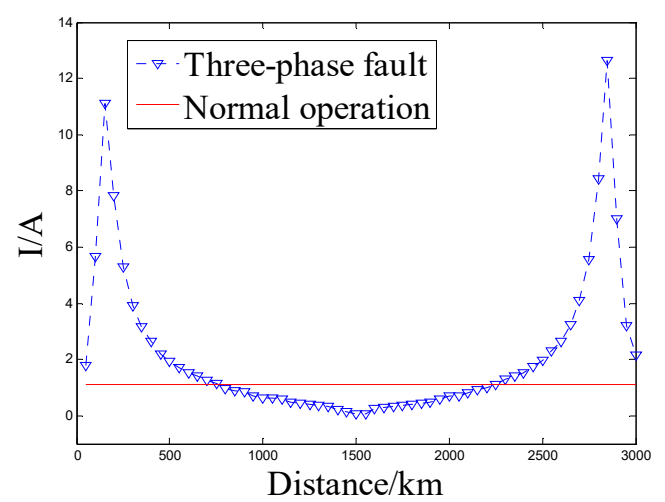

(c) Conventional differential current

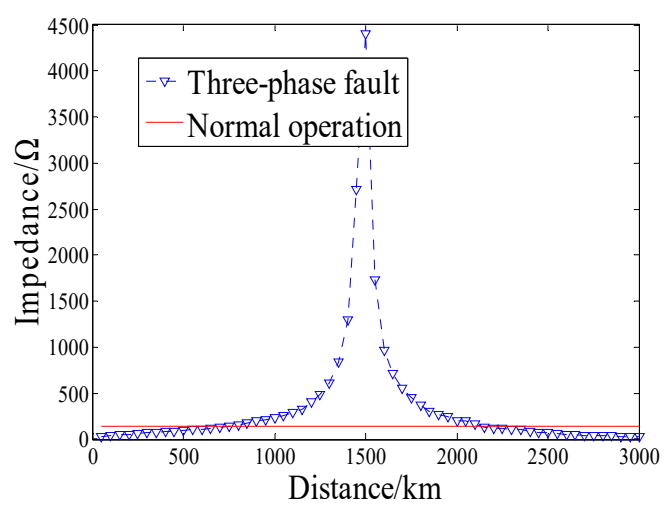

(d) The amplitude of M terminal impedance

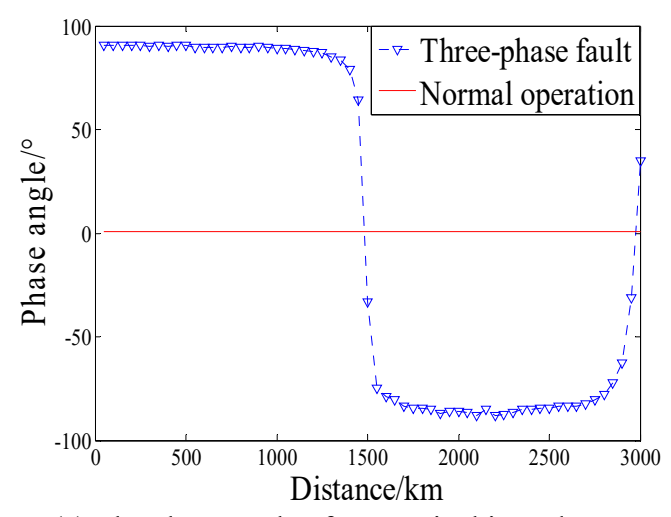

(e) The phase angle of $\mathrm{M}$ terminal impedance

Figure 2. The electrical quantity of $M$ terminal when three short circuit faults occur at different points

In order to improve the protection scheme, this paper divides the faults into three types. When a short circuit fault occurs between the $\mathrm{M}$ terminal and the $\mathrm{N}$ terminal, it is defined as an internal fault; when a short circuit fault 
occurs in the middle section between $1000 \mathrm{~km}$ and 2000 $\mathrm{km}$, it is defined as a fault in the middle section; and when a short circuit fault occurs outside the line, it is defined as an outside fault. The simulation duration time is set to $4 \mathrm{~s}$, the time to apply faults is set to $1 \mathrm{~s}$ and the duration time of fault is set to $3 \mathrm{~s}$.

The simulation results of the differential currents at the $\mathrm{M}$ and $\mathrm{N}$ terminals when three-phase short circuits occur at different locations are shown in Figure 3.

It shows that when short circuit faults occur at the $\mathrm{M}$ and $\mathrm{N}$ terminals, the amplitude of the Bergeron differential current at the $\mathrm{M}$ and $\mathrm{N}$ terminal is very large; but when the internal fault occurs at the midpoint and outside the area, the amplitude of the Bergeron differential current at the $\mathrm{M}$ terminal and the $\mathrm{N}$ terminal is very small. Other types of short-circuit faults have similar characteristics. Therefore, the simple Bergeron differential protection can only protect the area outside the middle section but cannot protect the entire halfwavelength transmission line.
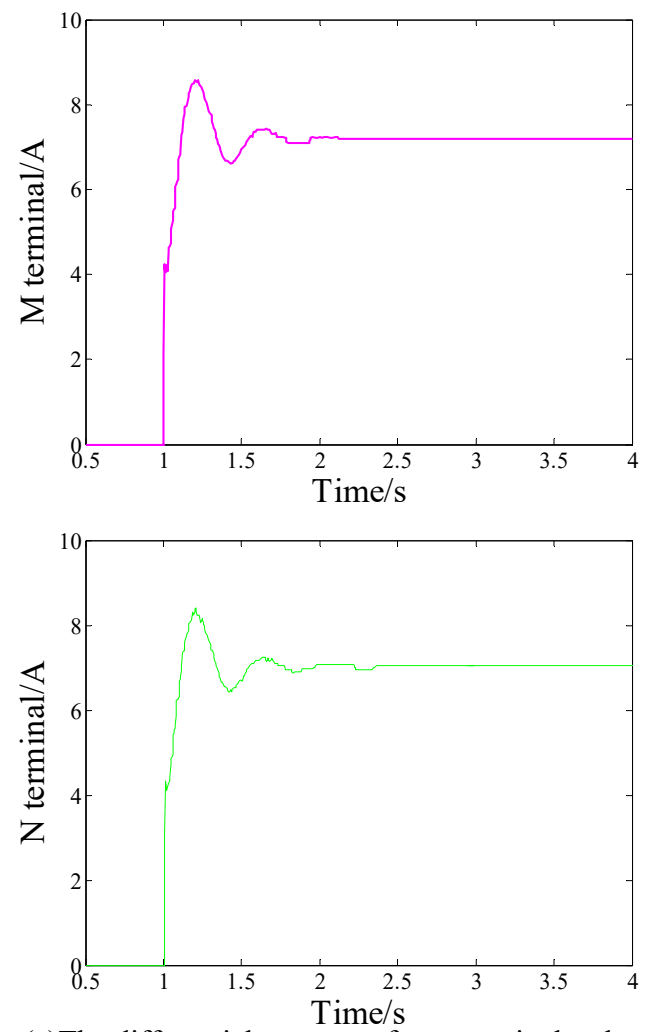

(a)The differential currents of two terminals when a three-phase short circuit fault occurs at $M$ terminal
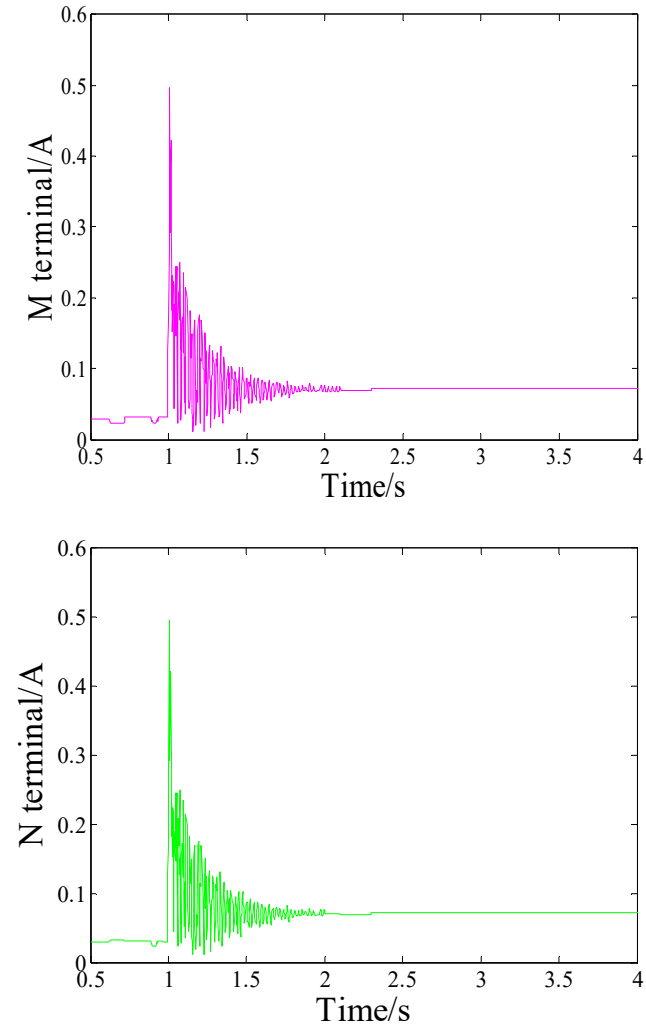

(b)The differential currents of two terminals when a three-phase short circuit fault occurs at midpoint
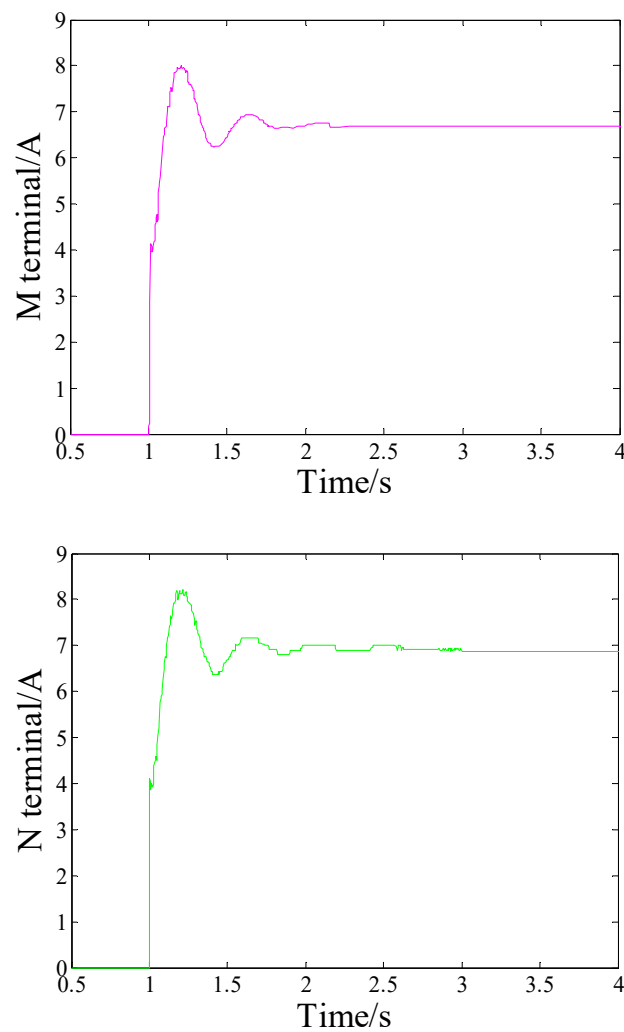

(c)The differential currents of two terminals when a three-phase short circuit fault occurs at $\mathrm{N}$ terminal 

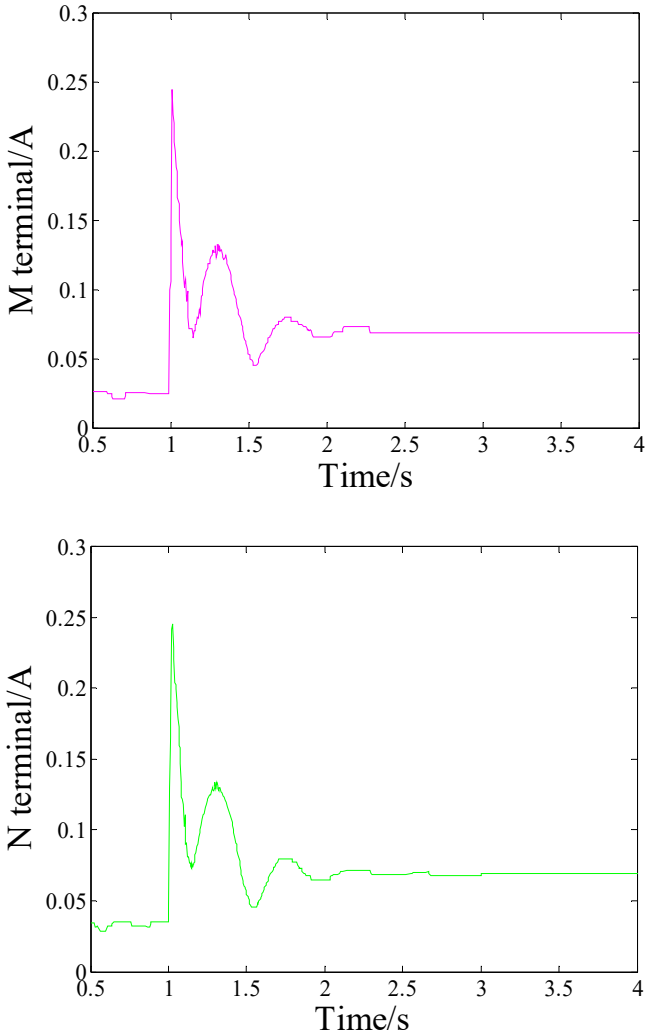

(d)The differential currents of two terminals when a three-phase short circuit fault occurs outside the zone

Figure 3. The Bergeron differential current of three-phase short circuit

According to the previous analysis, in order to improve the conventional Bergeron differential protection, it is necessary to choose a proper setting value of the low- sensitivity differential protection, that is, Imdset 1 in equation (9) and a proper setting value of the high-sensitivity differential protection, that is, $I_{m d s e t 2}$ in equation (10).

Moreover, it is necessary to get the setting value for judging the fault section, that is $I_{m s e t}$ in formula (11). Only considering the values of the secondary device, $I_{m d s e t}, I_{m d s e t}$ and $I_{m s e t}$ are set to $0.4 \mathrm{~A}, 0.1 \mathrm{~A}$ and $0.2 \mathrm{~A}$ respectively. By using the MATLAB, the simulation of Bergeron differential protection is improved so that high sensitivity can cooperate well with low sensitivity. The specific protection action time is shown in Table $1 \sim$ Table 4.

Table 1. Three-phase short circuit

\begin{tabular}{|c|c|c|c|c|c|}
\hline $\begin{array}{l}\text { Fault } \\
\text { point } \\
/ \mathrm{km}\end{array}$ & $\begin{array}{l}\mathrm{M} \\
\text { termin } \\
\text { al } \\
/ \mathrm{ms}\end{array}$ & $\begin{array}{l}\mathrm{N} \\
\text { termia } \\
1 \\
/ \mathrm{ms}\end{array}$ & $\begin{array}{l}\text { Fault } \\
\text { point } \\
/ \mathrm{km}\end{array}$ & $\begin{array}{l}\mathrm{M} \\
\text { terminal } \\
/ \mathrm{ms}\end{array}$ & $\begin{array}{l}\mathrm{N} \\
\text { terminal } \\
/ \mathrm{ms}\end{array}$ \\
\hline 0 & 9.9 & 19.8 & 1800 & 17.4 & 14.8 \\
\hline 300 & 13.2 & 21.6 & 2100 & 17.4 & 13.2 \\
\hline 600 & 16.6 & 22.4 & 2400 & 19.1 & 12.4 \\
\hline 900 & 19.1 & 22.4 & 2700 & 19.9 & 11.6 \\
\hline 1200 & 19.9 & 20.7 & 3000 & 19.8 & 9.8 \\
\hline 1500 & 63.8 & 63.8 & $\begin{array}{l}\text { Out- } \\
\text { side }\end{array}$ & $\begin{array}{l}\text { Don't } \\
\text { move }\end{array}$ & $\begin{array}{l}\text { Don't } \\
\text { move }\end{array}$ \\
\hline
\end{tabular}

Table 2. Single-phase short circuit

\begin{tabular}{|c|c|c|c|c|c|}
\hline $\begin{array}{l}\text { Fault } \\
\text { point } \\
/ \mathrm{km}\end{array}$ & $\begin{array}{l}\mathrm{M} \\
\text { termin } \\
\mathrm{al} / \mathrm{ms}\end{array}$ & $\begin{array}{l}\mathrm{N} \\
\text { termia } \\
1 / \mathrm{ms}\end{array}$ & $\begin{array}{l}\text { Fault } \\
\text { point/ } \\
\mathrm{km}\end{array}$ & $\begin{array}{l}\mathrm{M} \\
\text { terminal } \\
\text { / ms }\end{array}$ & $\begin{array}{l}\mathrm{N} \\
\text { terminal } \\
/ \mathrm{ms}\end{array}$ \\
\hline 0 & 9.7 & 20.3 & 1800 & 25.5 & 21.4 \\
\hline 300 & 12.3 & 21.4 & 2100 & 27.4 & 22.1 \\
\hline 600 & 21.5 & 28.1 & 2400 & 25.1 & 18.2 \\
\hline 900 & 26.5 & 26.5 & 2700 & 22.3 & 13.1 \\
\hline 1200 & 50.3 & 54.6 & 3000 & 19.7 & 9.4 \\
\hline 1500 & 67.1 & 71.5 & $\begin{array}{l}\text { Out- } \\
\text { side }\end{array}$ & $\begin{array}{l}\text { Don't } \\
\text { move }\end{array}$ & $\begin{array}{l}\text { Don't } \\
\text { move }\end{array}$ \\
\hline
\end{tabular}

Table 3. Two-phase ground short circuit

\begin{tabular}{|c|c|c|c|c|c|}
\hline $\begin{array}{l}\text { Fault } \\
\text { point } \\
/ \mathrm{km}\end{array}$ & $\begin{array}{l}\mathrm{M} \\
\text { termin } \\
\mathrm{al} / \mathrm{ms}\end{array}$ & $\begin{array}{l}\mathrm{N} \\
\text { termia } \\
1 / \mathrm{ms}\end{array}$ & $\begin{array}{l}\text { Fault } \\
\text { point/ } \\
\mathrm{km}\end{array}$ & $\begin{array}{l}\mathrm{M} \\
\text { termina } \\
1 / \mathrm{ms}\end{array}$ & $\begin{array}{l}\mathrm{N} \\
\text { termina } \\
1 / \mathrm{ms}\end{array}$ \\
\hline 0 & 9.1 & 19.1 & 1800 & 20.7 & 18.2 \\
\hline 300 & 14.9 & 23.2 & 2100 & 18.2 & 14.1 \\
\hline 600 & 15.7 & 25.7 & 2400 & 19.1 & 13.2 \\
\hline 900 & 14.9 & 18.2 & 2700 & 21.6 & 12.4 \\
\hline 1200 & 19.9 & 20.6 & 3000 & 21.6 & 9.9 \\
\hline 1500 & 61.6 & 64.9 & $\begin{array}{l}\text { Out- } \\
\text { side }\end{array}$ & $\begin{array}{l}\text { Don't } \\
\text { move }\end{array}$ & $\begin{array}{l}\text { Don't } \\
\text { move }\end{array}$ \\
\hline
\end{tabular}

Table 4. Two-phase short circuit

\begin{tabular}{|c|c|c|c|c|c|}
\hline $\begin{array}{l}\text { Fault } \\
\text { point } \\
/ \mathrm{km}\end{array}$ & $\begin{array}{l}\mathrm{M} \\
\text { termina } \\
1 / \mathrm{ms}\end{array}$ & $\begin{array}{l}\mathrm{N} \\
\text { termia } \\
1 / \mathrm{ms}\end{array}$ & $\begin{array}{l}\text { Fault } \\
\text { point/ } \\
\mathrm{km}\end{array}$ & $\begin{array}{l}\mathrm{M} \\
\text { terminal } \\
/ \mathrm{ms}\end{array}$ & $\begin{array}{l}\mathrm{N} \\
\text { terminal } \\
/ \mathrm{ms}\end{array}$ \\
\hline 0 & 9.1 & 19.1 & 1800 & 19.9 & 17.4 \\
\hline 300 & 15.7 & 24.1 & 2100 & 19.1 & 15.7 \\
\hline 600 & 14.9 & 20.7 & 2400 & 19.9 & 13.2 \\
\hline 900 & 14.9 & 18.2 & 2700 & 22.4 & 17.6 \\
\hline 1200 & 19.9 & 21.6 & 3000 & 22.4 & 12.3 \\
\hline 1500 & 64.9 & 68.2 & $\begin{array}{l}\text { Out- } \\
\text { side }\end{array}$ & $\begin{array}{l}\text { Don't } \\
\text { move }\end{array}$ & $\begin{array}{l}\text { Don't } \\
\text { move }\end{array}$ \\
\hline
\end{tabular}

From the analysis of Table $1 \sim$ Table 4 , it can be seen that the protection of high sensitivity cooperates well with low sensitivity, which makes the protection of the entire line come true. When a short circuit fault occurs at the $\mathrm{M}$ terminal and the $\mathrm{N}$ terminal, the Bergeron differential protection device at the $\mathrm{M}$ terminal acts quickly and can be completed within $10 \mathrm{~ms}$. When a fault occurs in the middle section of the line, a certain time delay is required to complete the action of the protection device. The protection action time at the middle point generally exceeds $60 \mathrm{~ms}$. When a fault occurs outside the line, the protection device will not operate. Generally speaking, the protection action time is within the range allowed by the actual project. The improved Bergeron differential protection scheme in this paper has high reliability and can significantly improve the safety of half-wavelength power transmission systems. 


\section{CONCLUSION}

Half-wavelength AC transmission line has long transmission distance and high voltage level, and its fault characteristics are significantly different from those of conventional transmission line. There are some problems in actual protection operation. For example, the capacitance current along the half-wavelength transmission line cannot be accurately calculated; the differential current is close to 0 when the fault occurs at the midpoint; transmission line has a long channel delay and the transmission time of electromagnetic wave gets longer. Therefore, conventional differential protection cannot be used on the half-wavelength transmission line.

This paper uses a new differential protection scheme which adopts the Bergeron model. In this protection scheme, several problems are solved well: the Bergeron model equals the distributed parameter element to the lumped parameter element, which eliminates the influence of the distributed capacitance current; in order to solve the problem of small fault current which is located at the midpoint of the line, a low setting value is used to improve the protection sensitivity; in order to reduce the protection action time, the protection scheme of two-stage quick action on the whole line and the delay action in the middle area are used. On the premise that the protection can operate correctly, the quick action is guaranteed to the greatest extent. Experimental results show that the various actions and performances of the protection device can meet the requirements for safe operation of half-wavelength transmission line.

\section{References}

1.F.S. Prabhakar , K. Parthasarathy , H.N. Ramachandra Rao, Performance of tuned halfwavelength power transmission lines $[J]$. IEEE Trans on Power Apparatus and Systems , 88,12(1969): 1795-1802.

2.C. Pulin, S. Hongchun, Y. Bo, et al. Analysis of electrical length compensation types for tuned halfwavelength transmission lines $[\mathrm{J}]$. International Journal of Electrical Power \& Energy Systems, 115(Feb.2020):105520.1-105520.11.

3.W. Huaxin, W. Jian, et al. Suppression of Secondary Arc for UHV Half-wavelength Transmission Lines[J]. High Volatage Apparatus, 54(Jun. 2018):0053-0059(in Chinese).

4.S. Qiuqin, L. Qingmin, et al. Experimental Research on Secondary Arcs of UHV Half-wavelength $A C$ Transmission Lines[J]. High Voltage Engineering, 38(Feb.2012):350-358(in Chinese).

5.Z. Qiping, L. Chenguang, W. Lei, Research on Resonance Point of Three-Phase Short Circuit Fault on Half-Wavelength ACTransmission Lines[J]. Power System Technology, 41,9(2017):27432748(in Chinese).

6.W. Ping, H. Bin, et al. Characteristics of Transient Recovery Voltage of Circuit Breakers in UHV AC
Half-wavelength Transmission System [J]. High Voltage Engineering, 44,001(2018):22-28(in Chinese).

7.J. Santiago, M. C. Tavares. Relevant factors for temporary overvoltages due to fault-resonance conditions on half-wavelength transmission lines [J]. Electric power systems research, 175(Oct.2019):105886.1-105886.12.

8.Z. Liuchun, Z. Cuixia, et al . Insulation coordination of UHV half-wavelength power transmission system $[J]$. Power System Technology , 35,9(2011): 13-16(in Chinese).

9.S. Yunting, Z. Xiao, et al . Economic analysis and reliability assessment of $U H V$ half-wavelength $A C$ transmission [J] . Power System Technology, 35,9(2011): 1-6(in Chinese).

10.G. Yarong, Z. Zexin, et al. Time Difference Method to Calculate the Optimal Differential Point of Halfwavelength AC Transmission Line Differential Protection [J]. Proceedings of the CSEE, 36,024(2016):6796-6801(in Chinese).

11.L. Xiao, D. Dingxiang, et al. Analysis for Differential Current Distribution and Adaptability of Differential Protection of Half-wavelength $A C$ Transmission Line. [J]. Proceedings of the CSEE, 36,024(2016):6802-6808(in Chinese).

12.L. Bin, G. Zixuan, et al. Bergeron Model Based Current Differential Protection Modified Algorithm for Half-wavelength Transmission Line[J]. Automation of Electric Power Systems, 41,6(2017):80-85.

13.T. Ning, C. Le, et al. Local-Measurement-Based High-Speed Protection for Half-Wavelength UHV Lines[J]. IEEE Transactions on Power Delivery, PP ,99(2020):1-1. 